\title{
Habits of a lifetime: Family dining patterns over the lifecourse of older Australians
}

\section{Cathy Banwell}

National Centre for Epidemiology and Population Health, Australian National University, Canberra, ACT, Australia

\section{Jane Dixon}

National Centre for Epidemiology and Population Health, Australian National University, Canberra, ACT, Australia

\section{Dorothy Broom}

National Centre for Epidemiology and Population Health, Australian National University, Canberra, ACT, Australia

\section{Anna Davies}

National Centre for Epidemiology and Population Health, Australian National University, Canberra, ACT, Australia

\section{ABSTRACT}

Here we examine how older Australians' accounts of family meals mirror shifts in the Australian way of life over the second half of the twentieth century coupled with their changing personal circumstances as they age. We provide qualitative accounts of these changes drawn from in-depth, semi-structured interviews with 111 men and women resident in greater Melbourne and born in the 1920s and 1930s. Mostly, study participants have retained many of the habits and practices of their youth, although changing domestic arrangements, aging and health concerns have impacted on their culinary habits. When young they learned to view food as a utilitarian necessity and this attitude has translated, in later life, into a concern for its health effects, often signalled by changing body weight and shape. The most obvious impact of evolving Australian foodscapes on their culinary habits is that they now dine out more frequently and consume a great diversity of food.

KEYwORDs: elderly Australians; family dining patterns; body mass index; health

\section{INTRODUCTION}

We had very cheap food, [it] would have been a lot of potatoes and a lot of rice, boiled rice, rice puddings, the whole bit. I imagine we had meat, but I don't actually recall. I would say it would be the cheaper cuts because my father was earning a pittance, an absolute pittance.
Joy is an elderly woman reflecting on the family meals from her childhood. Her account displays little nostalgia for the food of her youth, nor is it vividly detailed. Instead, she dwells prosaically on the categories of food she ate and their cost.

This paper uses recollections of food as a vehicle to bring the personal and the social together 
as Joy does. Her references to her father's earning capacity and the accompanying memory that her mother would always serve the husband and the four kids first, reflect the social and economic conditions of the time.

Here we examine how elderly Australians' accounts of family meals mirror shifts in the Australian way of life over the second half of the twentieth century and with their changing personal circumstances as they age. Our elderly participants have experienced considerable social and economic transformations over their lifetimes. The expansion of mass-produced cheap food, car use and screen-based entertainment in the home are implicated in the shifting energy balance of Western post-second world war populations (Dixon and Broom 2007; Prentice and Jebb 1995) leading to what has been acknowledged as an increasingly obesogenic environment and a concomitant growth in Australia's population weight (Australian Bureau of Statistics 2006) making it among the heaviest of the OECD countries (WHO 2005).

We consider how a generation of men and women born in the 1920s and 1930s respond to food-related social trends. This approach accords with what has been described as a 'synthesis' between a cohort and generation approach (Jackson and Heard 2000). A cohort is typically defined as a group of people who experience the same event at the same time (Jackson and Heard 2000). This study's cohort was born in a 20 -year time period and experienced the Depression, World War II and subsequent socio-economic changes, meaning that life events such as leaving home, getting married and having children occurred at similar times. It is this nexus between their age and simultaneous experience of life course events that produces identifiable patterned cohort effects. Furthermore, the social, economic and cultural conditions that a cohort experiences shape 'the outlook and life options and ultimately their life-time outcomes' (Jackson and Heard 2000). This understanding has most in common with the sociological concept of generations, which correspond to successive waves of new children who share a history and time period (Jackson and Heard 2000). Study participants match what Mackay calls the 'Lucky Generation' (1997); those who grew up in times of hardship and austerity but later enjoyed the prosperity of the post-war boom at a time in their lives (young adults) when they were best able to exploit it.

\section{A generation's memories}

Holtzman (2006) made two observations about the interconnection of memory and food that foreshadow two themes in this paper. One is that it 'is a locus for historically constructed identity'. Our participants had a particular relationship with, and view of food, that reflects an identity and world view that is unique to their generation. That a cohort or generation shares outlooks and dispositions is predicated upon a concept of shared memories of similar experiences. In line with the work of memory theorists (Connerton 1989; Golden 2005) we argue that memory is primarily socially constructed and collective. For Connerton 'the memories of one generation [are] locked irretrievably, as it were, in the bodies of that generation' (1989:3). Holtzman's other point is that 'dietary change [is] a marker of epochal shifts'. Participants' reminiscences of how they have adopted, adapted and resisted change to their immediate family foodscape provides an insight into the broader social and economic forces that have motivated change over the last 50 years in Australia.

However, this paper's focus is not primarily on memory although we note the particularly strong relationship between memory and food through the latter's ability to evoke emotional and embodied responses (Holtzman 2006; Sutton 2008). People are most likely to recall food occasions that involve social relationships with strong emotional salience (Lupton 1994). Memories of the same event sometimes diverge, raising questions about their accuracy and reliability but we agree with Lupton that it is not the 'truth' of recalled food events that is important but rather 
it is the 'construction of knowledges and the process by which the enculturation of individuals into society is achieved' (Lupton 1994:669). We too are concerned with these processes but unlike many studies of food recollections we dwell on the mundane and everyday domestic foodscape rather than special or highly memorable occasions. Perhaps for this reason, Joy's narrative illustrates yet another theme that is expanded upon later in this paper: the lack of pleasure in food.

\section{Methods}

This paper reports on part of a study that examined the contribution of broad social trends to the increasing weight of Australians over 50 years. It arose through a collaboration with the Melbourne Collaborative Cohort Study (MCCS, also Health 2000), a longitudinal study based at the Cancer Council of Victoria examining links between chronic diseases, diet and lifestyle. From a database of 40,000 cohort members, MCCS staff selected a sub-sample of 111 people who were invited to participate in this study. We obtained permission to access data on our subsample already collected by the MCCS.

More than 20 participants in each major category of interest (based on body mass index $[\mathrm{BMI}]$ and gender) were recruited so that we were able fully explore the range of experiences related to our topic and to capture subtle differences between sub-groups. Participants were randomly selected from a BMI range of less than or equal to 25 (categorized as a healthy weight) or from those who had a BMI over 30 (obese) so that we could search for qualitative differences in attitudes to, and experiences of, food. We selected only Anglo-Australians rather than exploring cultural differences across ethnic groups. Participants who had raised children were selected so that their adult children and grandchildren could participate in other components of the study. We aimed to recruit equal numbers of men and women but after the recruitment strategies described above were employed our sample contained more women than men. The Health 2000 study commenced with approximately $60 \%$ women and $40 \%$ men within the Australian/New Zealand heritage category; a ratio that is likely to include proportionally more women as the cohort ages and men on average die earlier.

We used a semi-structured interview schedule to guide interviewing which focused on three snapshots of participants' lives: childhood (when they were aged about 10-12); adult life (when their own children were aged about 10-12); and their lives at the time of the interviews. The approach shares much with the life history or narrative method used in anthropology, gender studies and other disciplines where the research offers an insight into the influence of culture on individual subjectivity (Ferzacca 2004). Before asking about the specific times described above, participants mapped out a time line of major life events (moving house, family births and deaths, leaving home, getting married, having children), allowing us to locate our age/period snapshots in the broader context of their lives. Food-related topics included descriptions of family meals, who was present and who prepared them. They were not asked specifically about their weight although we had access to the lifestyle questionnaires collected by the MCCS which included measured weight.

The interviews which usually lasted between one to two hours were conducted in rooms at the Cancer Council, a familiar location for the participants who repeatedly visit there to participate in successive waves of data collection for the MCCS. Interviews were audio-recorded and transcribed by an independent service. A coding framework was developed after an initial reading of a sub-sample of interviews and we then shared the subsequent coding task using Atlas Ti (Muhr and Friese 2004) to assist with the management of qualitative data. Team members coded each others' interviews as well as their own to minimise bias. Widely inclusive coding categories were used to ensure consistent coding and we met frequently to discuss coding progress. Text was coded 
by time period and generation as well as theme so that we could easily determine sections of text relating to, for example, family meals during a participant's childhood, during their children's childhood. Ethical clearance was obtained from the ANU Human Research Ethics Clearance and from the Cancer Council of Victoria.

\section{A PICTURE OF PARTICIPANTS}

Interviewees were aged on average in their mid-70s. The wide age-range of the group (almost 20 years) means that not all the group would have recalled the same historical periods with equal clarity. However, the sample is large enough for a substantial proportion of participants to remember the effects of major historical events on their daily lives. The cohort was comparatively well-educated with $36 \%$ reaching year 12 and 58\% (more men than women) undertaking some form of post-secondary training, often at night (Table 1). They were better educated than their parents of whom less

TABLE 1: Socio-demographIC CHARACTERISTICS OF STUdY PARTICIPANTS

\begin{tabular}{|c|c|c|c|c|}
\hline & & es & & es \\
\hline & No & Percent & No & Percent \\
\hline Age range (67-83) & 73 & 66 & 38 & 34 \\
\hline & & & & \\
\hline
\end{tabular}

\section{Education}

Up to and including year 8

23

Year 10

25

Year 12

23

Post-secondary education
Net household income per annum

Less than $\$ 30,000$

$\$ 31,000-\$ 70,000$

$\$ 71,000$ and over

BMI

$18.5-24.9$

Over 30
47

36

16

5

26
32

34

32

53

32
34
32

63

28

9

64

36
24

21

55

68

\section{Australian standard classification of occupation (ASCO)}

1 Managers and administrators

1

2 Professionals

10

3 Associate professionals

4 Tradespersons and related workers

5 Advanced clerical and service workers

6 Intermediate clerical, sales and service workers

7 Intermediate production and transport workers

8 Elementary clerical, sales and service workers

9 Labourers and related workers

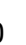

$\begin{array}{rrr}1 & 6 & 16 \\ 14 & 15 & 39 \\ 4 & 3 & 8 \\ 11 & 4 & 10 \\ 19 & 1 & 3 \\ 14 & 1 & 3 \\ 3 & 0 & 0 \\ 8 & 2 & 5 \\ 6 & 0 & 0\end{array}$


than $40 \%$ completed secondary schooling. At the time of the interviews (2006) most participants had household incomes below $\$ 71,000$ per annum with women concentrated in the lowest household income category of less than $\$ 30,000$. Sixty percent of interviewees labelled themselves as middle class. More people identified themselves as working class (20\%) than upper middle class (7\%) and none described themselves as upper class. Despite this egalitarian self-definition, only $53 \%$ of interviewees sent their children to public, government-run schools. As one would expect more men were concentrated in the managerial and professional categories while women were mainly located in the clerical, sales and service categories (Table 1). Their occupations were generally of higher status than their parents. For example, half of their mothers worked at home, while very few of their fathers were professionals or managers.

\section{FOOdSCAPES}

\section{Before and during WWII}

Before we examine participants' reflections on family meals in the context of the socio-cultural, economic and historical events that are the 'macro-contexts' (Sobal et al 2006) a general observation is required. Participants' memories and attitudes to family meals do not appear to be influenced by their fathers' occupations or class identification, even when comparing accounts of those who located themselves at the extreme ends of the scale (i.e. working class to upper middle class).

Participants grew up in a period of austerity (Mackay 1997). Some types of food were scarce during the Depression and then due to the war, rationing commenced in 1942 and continued until 1947. Butter, tea, sugar and meat were rationed and eggs were allocated to priority groups such as children under five years while sausages, offal, canned meat, poultry, rabbits, fish, bacon and ham remained unrationed (Australian Bureau of Statistics 1945). Nevertheless, only the poorest few reported being hungry, although almost everyone observed that food was basic.

They recalled that their families employed a number of strategies to stave off hunger and often prefaced their descriptions of childhood meals by saying things like Gosh, things were tight or we had very cheap food. Eve, (aged 75) described a typical evening meal:

But if we didn't have a lot of money, we didn't have a lot of food.... (Did you ever go hungry?) Never. My mother could make a meal out of nothing. (What kind of meat and vegetables would they have been?) Always potato, pumpkin and a green vegetable of some sort. Usually if sausages were cheap, chops were cheap; if it was cheap that was what mother bought.

Three features of this quotation are echoed in most accounts of childhood evening meals: food was humdrum and unexciting, consisting of meat and vegetables; they were dictated by the availability and affordability of foods at the time; and mothers were good at making ends meet, displaying a thriftiness and an ability to make do with what they had.

The weekly pattern of meals was also predictable as Heather (aged 73) recalled. Typically, much of the weekly food consumption hinged around the hot Sunday roast at lunchtime with left-overs supplying at least one other meal and cold meat used as filling for men's and children's lunchtime sandwiches.

We'd have a weekly roast with three vegetables and a sweet.... And that would usually be Sunday lunch. Sunday night it would be cold meat and salads and homemade scones just straight out of the oven.

Salads were summer fare and stews in winter. Meals consisted of lamb or beef, often sausages or chops, which were cheaper and steak less frequently, while chicken and other poultry were reserved for Christmas or other special occasions. At the time Australia was a major producer and exporter of sheep wool and meat. 
Some participants remembered their meat intake consisting almost entirely of lamb and mutton. Offal and game foods were also inexpensive and participants like Heather recalled eating lambs' brains, tripe and tongue.

People can't understand why I like offal. And brains and lambs fry and all that. But we were brought up on that during the food rationing (CB15).

Vegetables were usually potato, pumpkin and greens such as brussel sprouts, cabbage, cauliflower or peas. The family dinner frequently included a pudding or dessert which consisted of sweet carbohydrate combinations such as baked and steamed puddings or custards, with lighter desserts such as stewed fruit or jelly offered in summer. Desserts were a comparatively inexpensive way for mothers to display their culinary skills and satisfy hungry husbands and children. Homebaked scones and biscuits served a similar purpose and were often available for after school snacks.

The division of food labour was gendered: Heather recalled that women prepared cooked and preserved food and managed the provisioning of the household. While women's labour and thriftiness created meals from basic materials, men were vital to feeding the family. As breadwinners, their ability to earn an income was the main predictor of how much money was available to a family for food. Their importance was acknowledged at the dining table. Joy remembered that the family meal was served exactly at $5 \mathrm{pm}$ because that was when her father arrived home and he expected his meal to be ready:

He'd been out working and he used to walk 5 mile to work, 5 mile back. And when he got home, he'd be hungry, but 5 o'clock was dinner.

Joy's mother often ate her food cold because she always got up to serve Joy's father first and then interrupted her meal to get him his dessert when he'd finished his main course. Joy commented:
But this was the role of the housewife back then, the man coming in from work was the most important person. And the wife always, you know, was very, very low down on the ladder, definitely...

Children's lowerstatus was also evident. Family meals were not only dominated by some fathers' homecomings but also by their food preferences and their emotional states. Sixty-nine-year old Jenny recounted that her father insisted that the children were not allowed to talk at all. Children dined with the family and ate what they were given. We weren't allowed to have dislikes, I don't think, with five kids. I think we ate most things. They knew that food was scarce, particularly if rationed, and expensive. Helen said: Times were hard and you didn't waste anything. As children, they seemed to have absorbed this attitude with little resistance, even though they acknowledged it was a struggle to eat some foods. I can remember sort of chewing it and chewing it and chewing it and having to sort of swallow it... Helen continued. If they did not finish their meal they might be banished from the table, refused dessert or served their uneaten food for breakfast.

Becoming a teenager changed few of these norms and routines. Rarely did they eat at each others' houses; sometimes they knew that other families did not have food to share. Instead young people continued to conform to the family dining pattern until they left home to establish their own household or in a few cases went to the war where they were introduced to eating in mess halls. When they left home some women learned to cook for the first time if they had not been taught by their mothers. Heather remembers:

Oh she taught me to make everything, cakes and sweets and main courses and that. When I got married, [I] walked out with a beautiful recipe book from my mother with everything I needed in it.

High unemployment in Australia in the interWar years compelled men to find additional ways 
to provide for the family. Even city-dwelling men fished, hunted or scavenged so that rabbit pie or fresh fish occasionally appeared on family dinner tables. One woman described how her father would go to the nearby Sanatarium factory on his bicycle and buy a sackful of broken Vita Brits (cereal biscuits) which they would have for breakfast. Children often contributed to food provisioning by minding chickens, helping in the vegetable patch, or rabbit trapping.

During WWII the government launched a campaign to encourage men in particular to grow vegetables and raise fowls in suburban backyards. Fruit from trees in the garden supplemented the diet in many households. Participants consumed large amounts of fruit, both fresh and stewed, so much so that one woman refused to eat plums for the rest of her life. Neighbours shared or swapped their fruit, vegetables and eggs and extra food was often given to neighbouring families who were battling with no expectation of repayment. Urban dwellers purchased food from nearby local shops while bread, milk and other goods were often sold door-to-door from a van or a horse-drawn cart, providing the housewife with a convenient supply of fresh food items. Some suburban families had rural relatives who supplied them with meat and dairy produce. As rationing did not exist in 'outlying' rural areas (Australian Bureau of Statistics 1945) farming families had access to larger amounts of red meat, fresh milk, fresh eggs from the domestic chook pen and a vegetable garden.

As children, participants rarely consumed take-away or food cooked outside the home. Occasionally they bought fish and chips or were sent to take a pot or a saucepan down to the local Chinese café to bring home with food in it.

\section{The 50s to the 80s: Post-war prosperity}

The end of the war was followed in Australia as elsewhere by a well-documented period of comparative comfort, prosperity and stability during which most of interviewees married and raised children. Families responded to a new sense of plenty. One woman described how her family vegetable garden was converted into more decorative but less practical flower beds. Supermarkets first appeared in Australian suburbs in 1960 and were readily adopted, assisted by increasing car ownership which escalated rapidly after the war particularly with the local manufacture of the Holden. By 1961 there was almost one car per family (Symons 1984). With the supermarket encouraging large-scale weekly shopping, a car to carry home a weekly average of $50 \mathrm{~kg}$ of goods per household (Symons 1984), and massproduced refrigerators in which to store it, food purchasing changed notably. The rise of the supermarket was assisted by other technological innovations such as the introduction of television which enabled the increased penetration of advertised food products into the household (Dixon 2002).

By 1960, 70\% of Melbourne homes had a $\mathrm{TV}$, a staggering penetration in the four years since its introduction into Australia during the year of the Melbourne Olympics. A few people said that their family started eating evening meals around the television and, for a few it had a noticeable impact on family dining as Betty (aged 82) observed:

Sunday lunchtime yes when the men use to watch World of Sport and they'd come over to our place [to watch on our TV] ... and the time would [pass] and the roast would be waiting and then [mother] said, 'right no more roasts on Sunday'.

Australian foodways were exposed to a widening array of influences in the 1960s. Celebrity chefs introduced the idea that food was pleasurable while French cooking and dinner parties became a form of entertainment (Symons 2006) and cookbooks began including European and Asian dishes. This expanding interest in exotic foods was attributed to the arrival of post-war immigrants who brought ethnically diverse food and a culture of dining out to Australia 
and increasing Australian wealth and experience gained while travelling abroad. American food business models played a major role in expanding Australian experiences of sophisticated dining (Kirkby 2008). Fast food franchises began to arrive in the 1960s and early '70s offering efficiency and meal replacement services for the housewife. However, the growth in food outlets in the 1960s did not appear to have a big impact on participants despite continuing to expand over the next two decades. Others such as Symons (2006) and Kirkby (2008) also observed that dining out was not widely adopted until after the 1980s.

Despite socio-economic and cultural changes family meals showed surprisingly little variation during the 1960s-1970s when most participants were in their 30s-40s and their children were aged around 10-12. The most common description of the evening meal was still plain simple food. Jill a 69-year-old woman recalled meals at this time being:

Pretty much the same. Grilled chops and veggies and then I would probably have a sweet because it's like - the kids like and still like apple pie, apple sponge, stewed apples.

The evening family meal remained the centrepiece, with men the main income earners and women's labour centred on provisioning and preparing food along with other domestic tasks. Sam's account demonstrates an increasing availability and affordability of food rather than a cultural shift in attitudes to food or in the structure and content of meals.

Not a great deal[changed] except that there was more of it probably and perhaps a bigger variation, but more roast dinners, more roast lamb, but not a great deal had changed.

In 1972 in Australia, during the first wave of feminism women won the right to equal pay for equal work. Many women participants had volunteered their labour particularly when their children were young and later again when they 'retired' while some joined the paid labour market once their children left primary school. Exemplifying a common trend, 79-year old Mary still shouldered the burden of family cooking and provisioning (Santich 1995). Her account hints at an anxiety to be a proper mother by preparing good meals and undertaking complex scheduling to be available for her child after school finished.

Well they were still getting good meals. I would prepare it perhaps before I went to work. At that point I was only working part-time and (daughter) ... her school was at the back where we lived, so I would always take her to school and then I'd get the bus and get into, go to where I was working.... And then I'd catch a bus and that would get to the school when it was time for her to get out.

That some women stopped making desserts to save time suggests that desserts were not considered central to a good meal, although others still made desserts because of the importance their children attached to them. Frieda (aged 82) who was teaching while her children were at school, explains:

Yes, I had to cut out quite a bit of dessert making and relied on sometimes buying something. But also during the school holidays I used to make up a great big batch of desserts, puddings and have them in the freezer.

Rose, a 70-year old, noted that meals at this time were similar to those she had as a child except that she made fewer desserts which she first attributed to her laziness but later she said:

[We] probably had icecream or something like that. Stewed fruit maybe. I was going to work all that time and had the three kids and during that time I did a couple of uni courses.

She recounted that one child had questioned her mothering:

One of the (children) said, 'Why aren't you a real mummy?' I've never forgotten this, and 
I said, 'What do you mean?' and she said, 'You know, making biscuits and hot drinks when you come home from school'.

Rose's vivid memory of the exchange illustrates the potent nexus between mothering, love and food and the difficulties of asking mothers to disrupt it by asking children to eat food they don't like or not preparing the food they enjoy. Others have commented on the emphasis placed on desserts, sweets and puddings at this time (Duruz 1999; Symons 1984) with Duruz arguing that baking and making desserts was the 'public face' of feminine identity making in the 50s. Rose's story illustrates Duruz's argument that baking was a form of feminine gift giving that expressed love but was otherwise unrecognised and undervalued.

Rose's story illustrates yet another trend: the encroachment of industrially prepared food products into family dining, sometimes replacing food made at home from scratch. Records show that around this time women started to spend less time cooking although it was not because men increased their time in the kitchen (Duruz 1999). Rather, women's domestic services began to be purchased in the form of convenience foods, take-away foods and restaurant meals. The shift from home cooked desserts to ice-cream illustrates the trend to industrially prepared (convenience) foods which although not always more fattening than home prepared foods, are considered to have contributed to population weight gain (Ulijaszek 2006).

Although the food habits of participants appeared fairly engrained, new habits were slowly added to older ones. The word casserole replaced stew perhaps signifying a new acceptance of European culinary habits. Slowly people adopted the food that European immigrants had introduced such as salamis, pates, cheeses, olives, breads, continental biscuits, conserves, cured hams and coffee (Gollan 1987) and Mediterranean vegetables and pasta became more popular (Cameron 2004). Some participants began stir-frying vegetables, or cooking them Chinese style, rather than boiling them. Around this period and continuing over the next few decades, a greater diversity of vegetables (e.g. avocados, broccoli, eggplant, Asian greens) was incorporated into some families' diet and some began drinking wine regularly with their meals.

\section{Recent times: Nineties and noughties}

Because most participants had already retired they were cushioned from many of the major social and economic changes of the 1980s and 1990s. It is this 'lucky generation' of participants who benefited financially from economic policies that favoured the young when they were young and the elderly as they aged (Thomson 1999). Most interviewees had dined out rarely in the past but some now did so more frequently, reflecting their comfortable economic circumstances as well as increased opportunity with restaurants appearing in many local shopping centres. Joan, (aged 78), enjoys going out often for lunch thus avoiding late nights.

But then twice a week we go to lunch at the local hotel, it's very good. Or there's a couple of restaurants and we go to lunch every Tuesday and Friday, we'll go this afternoon (CB26).

Some patronised inexpensive buffets specifically aimed at seniors. It appears that dining establishments now recognised this specific market which implies a widespread change in the eating habits of older Australians. While dining out is generally viewed as a form of pleasure and entertainment (Martens and Warde 1997) some participants also were likely to adopt it for utilitarian reasons, such as to save the effort of cooking for two people.

\section{A lifetime of meals}

Three major and interconnected changes have occurred in participants' eating habits over their lives. First, they are now consuming a wider variety of foods in a wider variety of venues. 
While their diets are still surprisingly similar to those they grew up with, they tend to consume less red meat, less offal, more fish and a wider variety of vegetables cooked in different styles. Ethnically inspired foods such as pasta and stir fries are popular. Some, like 70-year old John had travelled extensively during retirement becoming open to a wide range of cuisines (Johnston and Baumann 2007) and particularly adopting those (e.g. Japanese) that are considered healthy (Bestor 2000).

We have been fortunate enough to travel to Japan on four occasions playing tennis.... And as a result we've fallen in love with Japanese food (CB6).

John and his partner were semi-vegetarians, eating white meat, tofu and vegetables at home while enjoying Japanese and Italian food at local suburban restaurants several times a week. The chance to eat out also liberates women from domesticity, as 71-year old Adrian admits somewhat reluctantly:

I quite prefer to eat at home rather than go out, but we go out because my wife does all the cooking and it's a break for her.

Increasing dietary diversity was not generally accompanied by a widespread adoption of convenience or heat and serve foods. They were considered useful on occasions but were believed to be less healthy and enjoyable than home cooked food, as 79-year old Marge suggests:

Sometimes if I'm a bit lazy if I come home late or something I can cook that heat and eat pasta] and it's not too bad. But I make a lot of soups, different soups and put them in the freezer in containers and then I can add rice or pasta and that's a meal.

Like other women in this study she was quick to label herself as lazy with its connotations of moral failing if she cut corners with her cooking suggesting that these women grew up believing that a commitment to provisioning the family was central to their view of themselves as good wives and mothers.

A second and related impact was due to changes in participants' domestic arrangements. Children leaving home or the death of a partner meant that they no longer cooked large meals prompting them to adapt their cooking styles. To efficiently maintain what they considered to be healthy diet of home cooked food many people adopted Marge's approach of cooking large amounts of food, freezing it in smaller portions and then heating it in the microwave. The rapid rise of the freezer was in part impelled by its relationship with the microwave (Shove and Southerton 2000). Although it is argued that modern freezers are a device of convenience allowing the re-scheduling of a busy life, our respondents employ them to maintain a healthy diet and avoid convenience foods. Being retired, they were not particularly short of time, although many lead active and engaged lives. Some men now cooked if their wives were sick, frail or had died although it was still the norm for women of this generation to do most of the cooking and taking responsibility for the family diet. Thus, changes in family living arrangements had a greater influence on food management rather than on food choice.

However, health concerns increasingly impacted upon participants' food choices as they aged. Many had the typical chronic diseases of the elderly such as heart disease, high blood pressure, diabetes and cancers. In response they had reduced the amount of red meat they consumed often replacing it with fish. They had substituted oil for butter, yoghurt for cream and they rarely ate desserts. They intended to reduce the amount of sugar and fat in their diets and they now closely followed health guidelines regarding adequate fruit and vegetable intake. Occasionally, a major health problem would precipitate a dramatic change in diet, such as the complete abstinence from a category of food. Gendered practices were reproduced through health concerns. Men commented about their wives watching what you 
eat. Women were burdened with responsibility for their male partners' health while men were permitted to display mild signs of resistance by eating badly on occasions (Broom and LenaghMaguire 2010). Participants' understandings of health clearly showed the effects of public health nutrition campaigns and shared similarities with others' concepts of healthy foods which should be fresh, homemade and unprocessed and part of a 'balanced' diet (Paquette 2005).

\section{Body weight: Our waists have gone}

Increasing body weight was a major motivator for dietary change even though many participants felt there was little they could do to modify it. In Australia an inverse association exists between BMI as an indication of weight status and socio-economic status (Australian Institute of Health and Welfare 2003), particularly among women. In the study sample more than $70 \%$ of respondents with high BMIs (>30) earned less than $\$ 30,000$ compared to less than $50 \%$ of those with a healthy weight. ${ }^{1}$ However, BMI was unrelated to any other class indicators in our study.

Nineteen percent of participants (21 out of 111) had put on more than $5 \mathrm{~kg}$ in the last five years. Of these, most (71\%) were women. Most of those who had gained this much weight had BMIs over 30 at the time of the research. Although more women were in this category, men on average put on more weight over the course of their adult life $(15 \mathrm{~kg})$ than women $(11 \mathrm{~kg})$. Women were more likely to attribute weight increases to the influence of contextual factors such as childbirth and mothering on their diet.

Probably since after I had [son]. I put on a lot of weight then.... Okay, I was looking after the children and that sort of thing, but being at home it's terribly tempting, as I said. Put the baby down for a nap and go and have a cup of coffee and a biscuit and that sort of thing.
Many attributed weight increases to general aging processes exacerbated by decreasing levels of activity due to an accident, illness or infirmity. They were resigned to the idea that their weight and age rose together and resisted the idea that they ate unhealthily.

Because women of my age - our waists have gone, you see. We've lost that - and she [Doctor] said, 'Well that's not funny, you're going to have to do something about that', you see, and I said, 'I think it is very hard ...', 'No, not if you eat sensibly ...' Well I think I do eat reasonably sensibly.

In contrast a few respondents found that their weight had dropped with ill-health, with the death of a partner or with some other major life event. This study and others (Paquette 2005), show that body weight is considered an important and visible indicator of healthiness and is a major reason for modifying diet.

\section{A Generation's tastes}

Our 'lucky generation's' memories of food, often reduced to meat and three veg, were quite consistent across the sample and, in contrast with accounts of food and 'sensory memory' from European societies (Counihan 2004; Sutton 2008), their accounts were not replete with nostalgia for fragrances and tastes. Instead their memories were often as much about how gender and age hierarchies were expressed in family meals. In contrast to Counihan's account of her Florentine subjects 'enthusiasm for eating' some remained uninterested throughout their lives. Seventy-five-year old May who was one of the few people who identified herself as upper middle class said, We eat to live rather then living to eat while 65-year old Fred showed his disdain when he commented, I'm not fussed about having the best cuts of meat for instance or caviar or anything, I'm not really fussed

\footnotetext{
${ }^{1}$ We note that BMI is an uncertain measure for the elderly. The ratio of fat to muscle increases and height decreases with age (Hardy and Kuh 2006). Our sample was designed to include both men and women with a BMI under 25 and over 30. Thus the number of people with high BMIs is a reflection of our sampling strategy rather than an indication of prevalence.
} 
about food. Expressions of pleasure in food or dining were rare although some enjoyed or liked eating particular items; bread and dripping, or sweet things like bread and jam, fruit or baby carrots.

The contrast between our participants' accounts of childhood meals and Europeans' accounts (Counihan 2004; Sutton 2008) may be explained by cultural and generational attributes. Drawing upon the Bourdiean notion of the 'taste of necessity' and the 'taste of freedom', Ochs et al (1995) propose that American families socialise their children into a taste for necessity by stressing food's nutritional and economic value, while the children of Italian-American families are raised to associate food with pleasure. Like depression populations elsewhere (Ferzacca 2004) our participants learned that the purpose of food, whether tasty or not, was to satisfy hunger. That this taste for the necessary has largely persisted over the course of their lives is evidenced by their consistent valuing of food for its nutritional and health qualities over those of pleasure and aesthetics; a stance that is further reinforced by an aging body and changes in family organisation (Sydner et al 2007). Indeed, in later life they sometimes expressed pleasure in, or desire for a particular food item, but then rejected it perhaps regretfully, for health reasons. At the same time food-related health discourses that could be associated with 'anti-pleasure' (Coveney and Bunton 2003) have developed over the course of their lives (Lupton 1996). Health and nutrition concerns which were almost invisible when they were young and food was scarcer have become more important as food has become cheaper and more accessible. Ironically, an international crosscultural study found that in countries where pleasure is taken in food there is an association with lower average BMI while a higher BMI is found in countries where health concerns are associated with food (Rozin 2005).

Following Bourdieu, one would expect class differences to influence participants' food preferences and practices but their accounts instead emphasise an ethic of egalitarianism, sharing and similarity rather than distinction. Turner and Edmund's study (2002) demonstrated that Australian elite of the following generation (the baby boomers) similarly did not use food-related cultural capital to distinguish themselves from other classes thus supporting their argument that Bourdieu's theories of class are not strictly applicable in Australia.

\section{Conclusion}

Participants' memories of childhood meals, where food was treated as a utilitarian necessity, have translated in later life into a concern for the health effects of food that overwhelm a nascent interest in the pleasures of dining. Their enduring approach to food is mirrored in other qualities associated with hardship and deprivation such as loyalty, saving rather than buying on credit, a strong work ethic and a sense of mutual obligation (Mackay 1997:17-19). Meanwhile, more frequent dining out and adoption of a greater diversity of foods are their main concessions to a changing food environment.

\section{References}

Australian Bureau of Statistics (1945) Year Book Australia 1944-45, 1301.1 Australian Bureau of Statistics: Canberra.

Australian Bureau of Statistics (2006) National health survey: Summary of results .4364.0 20042005 Australian Bureau of Statistics: Canberra. Australian Institute of Health and Welfare (2003) 'Differentials in overweight and obesity among adults 1989-90 to 2001' Bulletin 11:1-17.

Bestor, T. (2000) 'How Sushi went global' Foreign Policy 121:54-63.

Broom, D.; and Lenagh-Maguire, A. (2010) 'Gendered configurations of diabetes: From rules to exceptions' Journal of Gender Studies 19(2):195-209.

Cameron, E. (2004) The sixties Freemantle Arts Centre Press: Freemantle.

Connerton, P. (1989) How societies remember Cambridge University Press: Cambridge.

Counihan, C. (2004) Around the Tuscan table Routledge: New York and London.

Coveney, J.; and Bunton, R. (2003) 'In pursuit of the study of pleasure: Implications for health research and practice' Health 7:161-179. 
Dixon, J. (2002) The changing chicken: Chooks, cooks and culinary culture UNSW Press: Sydney.

Dixon, J.; and Broom, D. (eds) (2007) The seven deadly sins of obesity: How the modern world is making us fat? University of New South Wales Press: Sydney.

Duruz, J. (1999) 'Food as nostalgia: Eating the fifties and sixties' Australian Historical Studies 29:231-250.

Ferzacca, S. (2004) 'Lived food and judgments of taste at a time of disease' Medical Anthropology 23:41-67.

Golden, C. (2005) 'Where does memory reside, and why isn't it history?' American Anthropologist 107:270-274.

Gollan, A. (1987) The tradition of Australian cooking Australian National University Press: Canberra.

Hardy, R.; and Kuh, D. (2006) 'Commentary: BMI and mortality in the elderly - a life course perspective' International Journal of Epidemiology 35:179-180.

Holtzman, J. (2006) 'Food and memory' Annual Review of Anthropology 35:361-378.

Jackson, N.; and Heard, G. (2000) 'Population and globalisation: Australia in the 21st Century' in 10th Biennial conference of the Australian Population Association: Melbourne.

Johnston, J.; and Baumann, S. (2007) 'Democracy versus distinction: A study of omnivorousness in gourmet food writing' American Journal of Sociology 113:165-204.

Kirkby, D. (2008) 'From wharfie haunt to foodie haven: Modernity and the law in the transformation of the Australian working-class pub' Food, Culture and Society 11:29-48.

Lupton, D. (1994) 'Food, memory and meaning: The symbolic and social nature of food' The Sociological Review 42:664-685.

Lupton, D. (1996) Food, the body and the self Sage: London, Thousand Oaks, New Delhi.

Mackay, H. (1997) Generations: Baby boomers, their parents and their children Pan Macmillan: Sydney.

Martens, L.; and Warde, A. (1997) 'Urban pleasure? On the meaning of eating out in a northern city' in Caplan, C. (ed.) Food, health and identity Routledge: London and New York, pp. 131-150.
Muhr, T.; and Friese, S. (2004) Users manual for ATLAS.ti 5.0. Scientific Software Development: Berlin.

Ochs, E.; Pontecorvo, C.; and Fasulo, A. (1995) 'Socialising taste' Ethnos 60:7-46.

Paquette, M. (2005) 'Perceptions of health eating' Canadian Journal of Public Health 96:15-19.

Prentice, A.; and Jebb, S. (1995) 'Obesity in Britain: Gluttony or sloth’ British Medical Journal 311:437-439.

Rozin, P. (2005) 'The meaning of food in our lives: A cross-cultural perspective on eating and well-being' Journal of Nutrition Education Behaviour 37: S107-S112.

Santich, B. (1995) “'It's a chore!” Women's attitudes towards cooking' Australian Journal of Nutrition and Dietetics 52:11-13.

Shove, E.; and Southerton, D. (2000) 'Defrosting the freezer: From novelty to convenience' Journal of Material Culture 5:301-319.

Sobal, J.; Bisogni, C.; Devine, C.; and Jastran, M. (2006) 'A conceptual model of the food choice process over the life course' in Shepherd, R. and Raatsm, M. (eds) The psychology of food choice CABI: Cambridge, MA.

Sutton, D. (2008) 'A tale of Easter ovens: Food and collective memory' Social Research 75:157-180.

Sydner, Y.; Sidenvall, B.; Fjellstrom, C.; Raats, M.; and Lumbers, M. (2007) 'Food habits and foodworks: The life course perspective of older Europeans' Food, Culture and Society 10:367-387.

Symons, M. (1984) One continuous picnic Penguin: Ringwood, Victoria.

Symons, M. (2006) 'From grandmas to gourmets' Food, Culture and Society 9:179-200.

Thomson, D. (1999) 'How history is failing our families' Family Matters 52:12-18.

Turner, B.; and Edmunds, J. (2002) 'The distaste of taste: Bourdieu, cultural capital and the Australian postwar elite' Journal of Consumer Culture 2:219-240.

Ulijaszek, S. (2006) 'Obesity: A disorder of convenience' Obesity Reviews 8:183-187.

WHO (2005) The SuRF report: Surveillance of chronic disease risk factors.

Received 02 April 2010 Accepted 23 June 2010 